\title{
Photoacoustic Technique Applied to Skin Research: Characterization of Tissue, Topically Applied Products and Transdermal Drug Delivery
}

\author{
Jociely P. Mota, Jorge L.C. Carvalho, Sérgio S. Carvalho and Paulo R. Barja \\ UNIVAP \\ Brazil
}

\section{Introduction}

The photoacoustic (PA) effect basically consists in the production of acoustic waves due to the absorption of modulated (or pulsed) radiation by a sample. Graham Bell discovered the PA effect in 1880, when he noticed that the incidence of modulated light on a diaphragm connected to a tube produced sound. Thereafter, Bell studied the PA effect in liquids and gases, showing that the intensity of the acoustic signal observed depended on the absorption of light by the material.

In the nineteenth century, it was known that the heating of a gas in a closed chamber produced pressure and volume changes in this gas. However, there were many different theories to explain the PA effect. Rayleigh said that the effect was due to the movement of the solid diaphragm. Bell believed that the incidence of light on a porous sample expanded its particles, producing a cycle of air expulsion and reabsorption in the sample pores. Both were contested by Preece, who pointed the expansion/contraction of the gas layer inside the photoacoustic cell as cause of the phenomenon. Mercadier explained the effect conceiving what we call today thermal diffusion mechanism: the periodic heating of the sample is transferred to the surrounding gas layer, generating pressure oscillations.

The lack of a suitable detector for the PA signal made the interest in this area decline until the invention of the microphone. Even then, research in this field was restricted to applications in gas analysis up to 1973, when Rosencwaig started to use the PA technique in spectroscopic studies of solids and, together with Gersho, developed a mathematical model for the generation of the PA signal in solid samples - the Rosencwaig-Gersho (RG) Model (Rosencwaig \& Gersho, 1976).

In condensed matter samples, one of the most important mechanisms for PA signal generation is the thermal diffusion, classically described by the RG model. According to this model, the (modulated) radiation absorbed by condensed matter samples is converted into heat, causing temperature modulation in the surrounding atmosphere. This eventually produces the mechanical effect of periodic expansion and contraction originating sound waves that can be detected by a microphone.

Since the publishing of the RG model and, soon after that, of the generalized theory for the PA effect by McDonald and Wetsel (1978), the PA technique has already proved its 
relevance in a large number of very different fields, from the polymerization of dental resins (Balderas-Lopez et al., 1999) to photosynthesis studies (Malkin \& Puchenkov, 1997; Herbert et al., 2000).

\subsection{Objectives}

The purpose of this chapter is to present applications of the PA technique in skin research, both in the characterization of skin itself and in transdermal drug delivery studies. The basic experimental setup for such studies will be briefly presented, aiming to help those who may be interested in developing similar studies. Emphasis will be done to in vivo measurements, because of its importance in this field. Our objective is to show the usefulness of the PA technique in the biomedical field, particularly in skin research; finally, perspectives for future work in this field will be presented.

\section{Photoacoustic measurements}

\subsection{Basic experimental setup}

Figure 1 presents one scheme for a basic photoacoustic experimental setup.

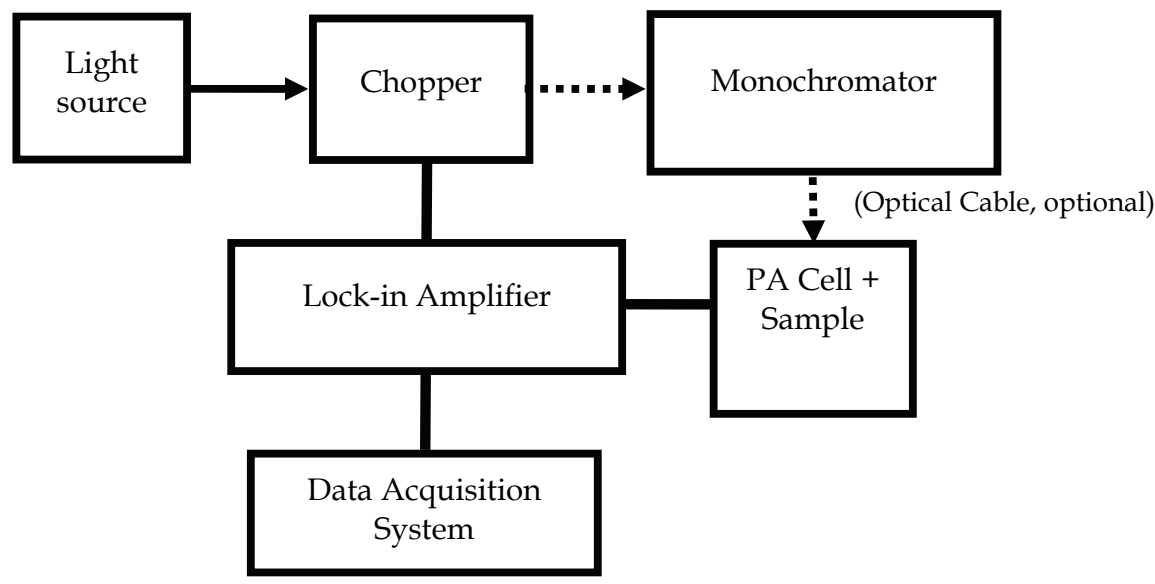

Fig. 1. Example of a basic photoacoustic experimental setup (scheme)

The experimental scheme in Figure 1 shows a (typically mechanical) chopper positioned in front of the light source, in order to modulate the radiation that comes into a monochromator (utilized in PA spectrocopy measurements). Light absorbed by the sample generates acoustic waves inside the PA cell; the PA signal is captured by a microphone (inside the PA cell) that sends it to the lock-in amplifier (also connected to the chopper, to receive information on the frequency modulation). The lock-in amplifier is connected to a microcomputer for data acquisition. In vivo, skin measurements are performed with an open-ended PA cell, in which it is the sample itself that closes the chamber.

\subsection{Measurements as a function of time}

The PA signal depends on the optical and thermal properties of the sample, which may vary with time due to different factors. When a sample undergoes changes in its 
composition or structure (as it occurs during the polimerization of a dental resin, for instance), the propagation of heat inside the sample is also modified, thereby altering the PA signal.

We must also mention the possibility of performing photosynthesis studies using PA measurements as a function of time (W.J. Silva et al., 1995). When PA measurements are performed in photosynthesizing samples as plant leaves, the PA signal presents, in addition to the photothermal component, a photobaric component, resulting from the gas exchanges associated to the photosynthesis process (Acosta-Avalos et al., 1996). This allows the study of the so-called photosynthetic induction, that is, the increase of the net photosynthetic rate that occurs when a plant is shifted from darkness to light (Sui et al., 2011).

As stated by Bodzenta et al. (2002) in their work on PA detection of drug diffusion into a membrane, PA measurements give the possibility for investigations in relatively long time periods. This makes the PA technique suitable for the monitoring of dehydration processes (Lopez et al., 2005) and of changes occurring in time in biological tissues such as skin. It is possible to study, for example, the kinetics of transdermal drug delivery through the analysis of PA measurements as a function of time. One example will be presented at the section 4 of the present chapter.

\subsection{Studies on the modulation frequency: depth profile}

In thermally thick samples (as skin tissue), only the light absorbed within the first thermal diffusion length $\left(\mu_{\mathrm{T}}\right)$ of the sample/tissue contributes to the PA signal (Rosencwaig, 1980). As the thermal diffusion length depends on the modulation frequency (f) of the incident light by the relation

$$
\mu_{T}=\sqrt{\frac{\alpha}{\pi f}}
$$

where $\alpha$ is the thermal diffusivity of the sample, it is possible to perform depth-profile studies, with the evaluation of the penetration depth of a product (or even a microorganism) in tissue. The possibility of performing depth-profile studies is particularly interesting in the characterization of multilayer systems (as skin itself).

The frequency dependence analysis of the PA signal can also be employed in the determination of the thermal properties (thermal diffusivity, thermal effusivity) of a sample or material (Balderas-Lopez \& Mandelis, 2001), including biological tissues as porcine skin (Gao et al., 2005; Qiu et al., 2008).

\subsection{Measurements as a function of the wavelength: Photoacoustic spectroscopy}

Photoacoustic spectroscopy (PAS) is already incorporated to the roll of useful photothermal techniques since the 1980s (Rosencwaig, 1980; Vargas \& Miranda, 1988). Besides the possibility of rendering depth-profile analysis in multi-layered samples, PAS presents at least two additional advantages over other spectroscopy techniques: i) as transmitted and reflected light do not interfere in PAS measurements, it is a "more direct" technique, representing a direct measurement of the light absorption by the sample; ii) it allows the study of optically opaque and highly scattering samples (which could not be analyzed by conventional optical spectroscopy). 
In PAS measurements, the emission spectra of the light source is typically obtained through measurements using black carbon powder (or other black material) as the sample, with all the remaining measurements being normalized with respect to the lamp spectrum.

PAS can also be employed in skin research. In 2004, Benamar and co-workers presented a PAS study on the effect of dihydroxyacetone, frequently employed for artificial tan. Measurements were carried out in the presence and absence of dimethylisosorbide (a solvent for dihydroxyacetone), on excised human skin. By monitoring the PAS signal intensity with time in the UV (300-400nm) range, these authors demonstrated that dihydroxyacetone in combination with dimethylisosorbide enhances the process of tanning (Benamar et al., 2004).

Recently, Melo et al. (2011) applied PAS to evaluate the penetration rate of Helicteres gardneriana extract, topically applied for anti-inflammatory purposes. Experiments were conducted ex vivo in mice. Croton oil was applied into both mouse's right and left auricles to induce inflammatory response, and the left auricle was treated with the extract. The strong anti-inflammatory effect observed for the Helicteres gardneriana extract was associated with the deep percutaneous penetration observed for the formulation, according to PA data (Melo et al., 2011).

\subsection{Photoacoustic imaging and tomography}

Photoacoustic imaging is based on the production of acoustic waves following irradiation by a short pulse of light whose absorption generates local heating and transient thermoelastic expansion (Balogun et al., 2009). According to Beard (2009), haemoglobin "represents the most important source of endogenous contrast" in PA imaging. This makes the technique particularly indicated to studying tissue abnormalities as tumors and other diseases related to changes in the structure and oxygenation status of the vasculature (Beard, 2009).

Recently, Hu and Wang (2010) presented "PA tomography" as a method combining high spatial resolution and optical absorption contrast, important in microvascular imaging and characterization. Reviewing the "major embodiments of PA tomography" (microscopy, computed tomography and endoscopy), they have analyzed the methods employed in different studies, including hemodynamic monitoring, determination of hemoglobin concentration, evaluation of oxygen saturation, studies of blood flow and tumor-vascular interaction.

Besides being applied to soft tissues, PA imaging can also be employed to hard tissues. Li and Dewhurst (2010) have applied a PA imaging system with a near-infrared (NIR) pulsed laser to obtain images from both soft tissue and post-mortem dental samples. They have also performed simulations (based on the thermoelastic effect) to predict initial temperature and pressure fields within a tooth sample, observing that values are maintained below the corresponding safety limits. In this way, the results presented by $\mathrm{Li}$ and Dewhurst show that the PA technique can be sucessfully applied to image both soft and hard tissues.

\section{Photoacoustic measurements and the characterization of skin}

Biological materials are sometimes difficult to study employing conventional techniques that require previous preparation of the samples, because these materials can have its properties significantly altered by preparation processes as solubilization, for example. The PA technique does not require previous preparation; it can be described as a non-invasive technique that allows even in vivo measurements. 
In general, biological tissues can be characterized as highly scattering samples; however, this is not a problem for PA mesurements, in which the signal is based in the direct absorption of radiation. As pointed by Cahen and co-workers (1980), "the relative insensitivity to scattered light of the PA signal makes such measurement an attractive way to measure biological samples in vivo". These features explain the potential of the PA technique in the study of opaque materials and complex biological systems such as skin. PA measurements can be employed to determine the absorption characteristics of the skin itself or topically applied products, as well as kinetic changes related to transdermal drug delivery.

Skin diseases can also be studied through PA measurements. In 2010, Swearingen et al. developed a PA methodology to determine the nature of skin lesions (pigmented and vascular) in vivo, which is important because misdiagnosis may even lead to cancerous lesions not receiving proper medical care. These authors irradiated skin with two laser wavelengths (422 and 530nm), with the relative response at these two wavelengths $(422 \mathrm{~nm} / 530 \mathrm{~nm})$ indicating whether the lesion is pigmented or vascular, due to the distinct absorption spectrum of melanin and hemoglobin (Swearingen et al., 2010).

\subsection{Skin type classification}

Skin type classification is important not only for medical or clinical purposes, but also for pharmaceutical and cosmetic industries, following the idea that an objective, precise characterization of skin could be useful in the design of new topically applied products and in defining more specific skin treatments according to each skin type.

However, in dermatology, there is still no universal agreement about the best method for classifying skin, as even the widely accepted method proposed by Fitzpatrick (1988) defining the so-called "skin phototypes" - is based in clinical, subjective analysis.

More recently, Baumann (2006a, 2006b) proposed a new skin type classification, according to which 16 different skin types are defined from the combination of four parameters, as skin can be characterized as: i) pigmented or nonpigmented; ii) dry or oily; iii) sensitive or resistant; and iv) wrinkled or tight. Baumann's skin typing is based on an extensive research, performed with 1400 volunteers. However, it relies essentially on the response of volunteers to a questionnaire; therefore, it does not fulfill "per se" the need of an objective classification, which would require experimental evaluation.

PA measurements have a potentially important role to play in an experimental approach to skin type classification. In 2000, Schmidt and co-workers conducted non-contacting, in vivo PAS measurements in skin (performed in 50 volunteers), in the VIS-NIR range, seeking an objective determination of pigmentation, blood microcirculation and water content of human skin (Schmidt et al., 2000). According to these authors, strong spectral variations observed within the same skin type are probably based on the natural variability of human skin and in the subjective clinical evaluation of the skin type; nevertheless, PAS results obtained show good correlation between PA data and (clinically evaluated) skin type, indicating that skin type determination could indeed be performed through the analysis of PA measurements.

\subsection{Skin pigmentation analysis employing photoacoustic measurements}

In 2004, Viator and co-workers proposed a method for the determination of the epidermal melanin content employing a PA probe using a Nd:YAG (neodymium, yttrium, aluminum, garnet) laser at 532nm (Viator et al., 2004). Ten human subjects with skin phototypes I-VI 
were tested using the PA probe and visible reflectance spectroscopy (VRS); melanin content was evaluated through each of these methods, and a good linear fit $\left(\mathrm{r}^{2}=0.85\right)$ was obtained for the plot of PA $x$ VRS.

Pigmentation skin level can also be evaluated through simple, direct PA measurements employing non-laser light sources. Actually, PA measurements have been performed at the Laboratory of Photoacoustic Technique Applied to Biological Systems (FASBio), at UNIVAP (Brazil). The objective of such in vivo measurements was to classify different skin types according to the amplitude of the PA signal, which can be associated to the corresponding pigmentation level of the skin.

In the following subsections, we present this straightforward PA approach to skin characterization according to the level of pigmentation, employing PA measurements in volunteers. Experimental results are compared both to Fitzpatrick and Baumann clinical skin type evaluations.

\subsubsection{Materials and methods}

The PA setup employed in such in vivo skin measurements consisted of a 250W tungsten halogen lamp as light source (with wavelength range $400 \mathrm{~nm}<\lambda<700 \mathrm{~nm}$ and light intensity of about $20 \mathrm{~W} / \mathrm{m}^{2}$ ), a mechanical chopper (SRS, model SR540), a lock-in amplifier (SRS, model SR530) and a microcomputer for data acquisition.

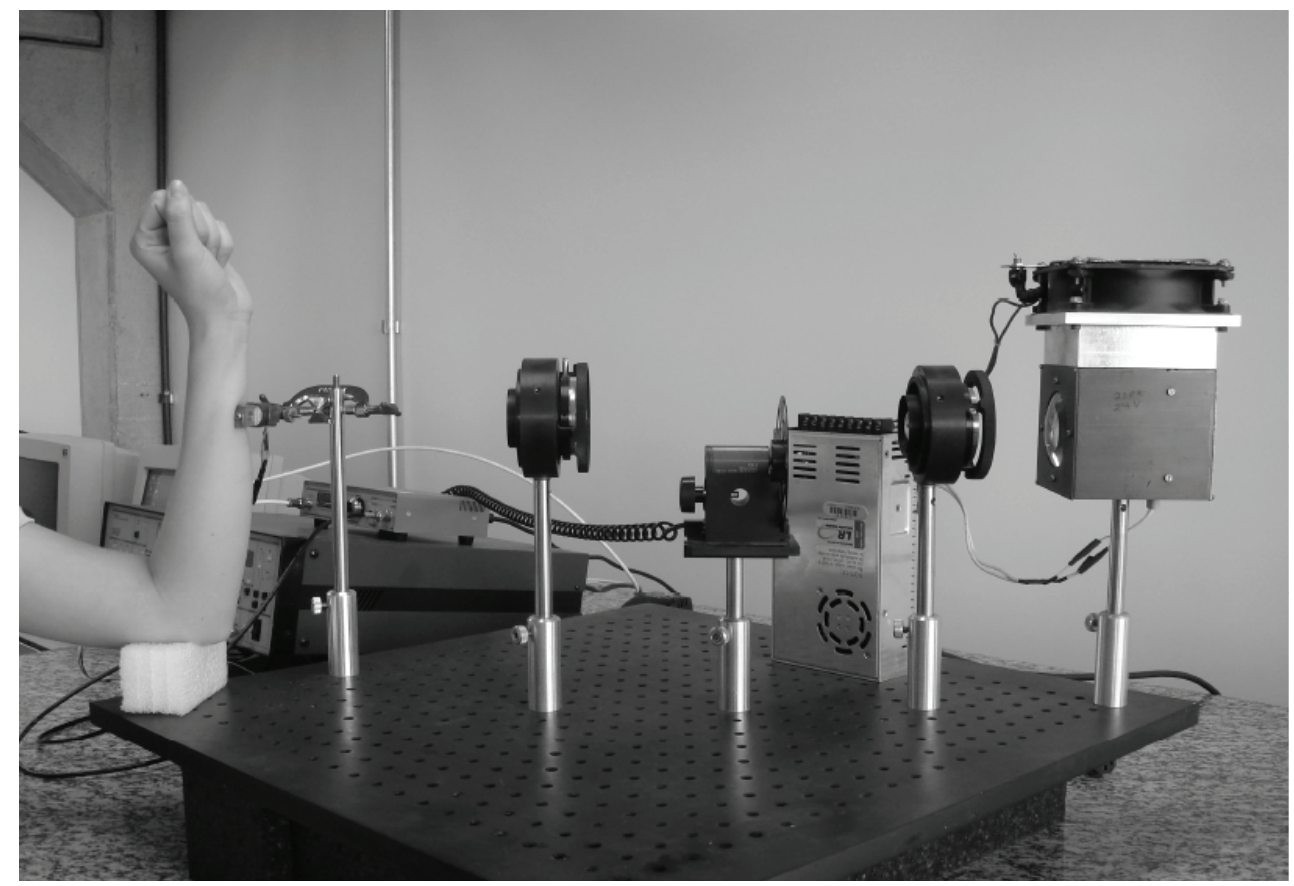

Fig. 2. Experimental setup with volunteer positioned for in vivo skin measurement

The double faced PA cell employed, with an electret microphone, was developed at UNIVAP; sensitivity was $15 \mathrm{mV} / \mathrm{Pa}$ for the frequency employed in skin measurements, 
17Hz. The electret microphone structure was described by Marquezini et al. (1990). The PA cell has a cylindrical body and two opposite, parallel faces (one is closed by a thin glass layer and the other, by the sample itself). For the modulation frequency employed $(17 \mathrm{~Hz})$, the thickness of the skin layer under study is about $30 \mu \mathrm{m}$.

PA measurements were recorded as a function of time (200 readings for each measurement, in $0.5 \mathrm{~s}$ intervals, up to a total of $100 \mathrm{~s}$ per measurement). During measurements, one face of the PA cell was closed with a thin transparent window, while the forearm of the volunteer was gently pressed against the opposite face.

Figure 2 shows the PA experimental setup employed for in vivo skin measurements at the FASBio/UNIVAP, with a volunteer positioned for measurement.

Measurements were performed in 57 female volunteers, between 20 and 30 years-old. Initially, each volunteer answered a questionnaire according to their daily routine associated to skin care; volunteers were also clinically evaluated and, as a result, they were classified according to skin phototype, following Fitzpatrick classification (Fitzpatrick, 1988).

Before measurements, the skin area to be evaluated was cleaned with cotton embedded in alcohol $70 \%$. The PA signal was then recorded for the inner and outer faces of both forearms. Volunteers were then classified according to the respective PA signal amplitude, and this classification was compared to the phototype classification.

\subsubsection{Results and discussion}

Initially, a comparison between the PA signal amplitude of the inner and outer faces was performed, showing a highly significant statistical difference (paired t-test, $p<0,005$ ), with higher PA amplitude being observed for the outer face of the forearm. This result can be attributed to the higher pigmentation level of the skin region continuously exposed to solar radiation, demonstrating that skin constitution and aspect are clearly influenced by the level of sun exposure.

After clinical evaluation of the volunteers for skin phototype (following Fitzpatrick classification), PA results were grouped according to the phototype of each volunteer. Results are presented in Table 1.

\begin{tabular}{|c|c|}
\hline Skin phototype (Fitzpatrick) & PA signal amplitude (mV) \\
\hline II & $1.26 \pm 0.05 \mathrm{a}$ \\
\hline III & $1.59 \pm 0.09 \mathrm{ab}$ \\
\hline IV & $1.70 \pm 0.10 \mathrm{ab}$ \\
\hline V & $1.80 \pm 0.10 \mathrm{~b}$ \\
\hline
\end{tabular}

Table 1. PA signal amplitude $(\mathrm{mV})$ for the inner face of the forearm, for each skin phototype (average \pm standard error). Different indexes $(a, b)$ indicate significant statistical difference (comparison among groups: $\mathrm{p}=0.009$, ANOVA)

Comparison among phototype groups was performed and significant statistical difference was verified (as we can see in Table 1), showing that the PA signal level (amplitude) for the inner forearm tends to scale with skin phototype, as defined by Fitzpatrick.

Afterwards, the PA signal amplitude for each volunteer (average values for the inner face of the forearm) allowed the division of the volunteers in two groups, "pigmented" (P) and "non-pigmented" (NP), following the Baumann proposal. As the average PA signal 
amplitude obtained for all measurements (inner face of the forearm) was $1.5 \mathrm{mV}$, this was the cutoff value adopted for separating the volunteers into " $\mathrm{P}$ " (for PA signal amplitude above $1.5 \mathrm{mV}$ ) and "NP" (under $1.5 \mathrm{mV}$ ). Table 2 shows the division of each (clinically evaluated) phototype group into the (experimentally evaluated) P and NP groups. In this way, the PA technique allowed the comparison between two different skin classification forms.

\begin{tabular}{|c|c|c|}
\hline Skin phototype & NP group (\%) & P group (\%) \\
\hline II & 93 & 7 \\
\hline III & 46 & 54 \\
\hline IV & 31 & 69 \\
\hline V & 20 & 80 \\
\hline
\end{tabular}

Table 2. Distribution of the volunteers of each phototype in the NP and P groups, according to the PA signal level

Table 2 shows that phototype II is highly related to the NP group, while phototypes IV and $\mathrm{V}$ concentrate in the P group. Phototype III appears in both groups, showing the variability of elements inside this classification.

The simple methodology presented here and the corresponding results obtained open perspectives for an objective, experimental classification of skin types, based upon PA measurements. Additional work in this field is currently being performed at FASBio/UNIVAP (Brazil).

\section{Transdermal drug delivery}

\subsection{Topical application of drugs: advantages and requirements for evaluation}

Topical application of drugs is known as an interesting alternative route to oral and intravenous administration, both aiming to systemic effects and local action, offering advantages such as ease of administration and lack of first-pass effect (Aqil et al., 2007). However, in studies of transdermal drug delivery (penetration of substances into skin), one must employ non-invasive techniques, in order to avoid second order effects that would at least bring difficulties to the interpretation of the results. In vivo measurements are particularly desirable in such studies, because the response of excised skin can be affected by dehydration, and the response of artificial skin differs significantly from that of in vivo skin at least in some cases - as when we talk about in-depth processes, in which even blood circulation may play a role.

As mentioned earlier in the present chapter, the PA technique can be applied without previous preparation of the samples and even for in vivo measurements; as such, transdermal drug delivery studies have been performed employing the PA technique in order to obtain the penetration rate of a wide range of different products topically applied to skin (Bernengo et al., 1998; Hahn et al., 2001; Savateeva et al., 2001; Pedrochi et al., 2005; Truite et al., 2007).

\subsection{Substrates for transdermal drug delivery studies}

Besides measurements in human skin, penetration rates of topically applied products are frequently evaluated through measurements performed in animal skin tissue. In this case, 
rabbit and pig skin are, by far, the most employed alternatives, because of the similarity to human skin.

As pointed by Simon \& Malbach (2000), physiological and anatomical similarities between man and pig make this animal a good model for man in biomedical research. The correlation of quantitative data between pig skin and human skin can be frequently classified as very good (Benech-Kieffer et al., 2000); therefore, pharmacological (and even toxicological) skin research is often based on the knowledge of pig skin absorption and percutaneous permeation.

Recently, Nicoli et al. (2008) employed qualitative and quantitative analysis of stratum corneum lipids and permeation experiments to analyze the utilization of rabbit ear skin in transdermal permeation studies, using pig ear skin as a reference. Their results showed that the stratum corneum of both rabbit ear skin and pig ear skin present similar thickness. Probably due to its higher lipophilicity, rabbit ear skin was less permeable to hydrophilic compounds; however, the permeability to progesterone was comparable between isolated pig epidermis and rabbit ear skin. Nicoli and co-workers conclude that the rabbit ear skin can be sucessfully employed in skin permeatin studies.

\subsection{Photoacoustic evaluation of topically applied products}

Different pharmaceutical formulations for a topically applied drug may present very different transdermal delivery ratios, depending on the product composition (excipients usually play a major role in the penetration kinetics of topically applied products). These penetration rates may be evaluated through the analysis of the time-dependence of the PA signal after topical application of a given product in skin. This methodology can also be applied to the evaluation of sunscreens, that may be characterized in terms of their (photo)stability after topical application (in this case, the lower the rate, the better the product).

Gutierrez-Juarez et al. (2002) employed PA measurements in the analysis of substances topically applied to the human skin. To fulfill this purpose, these authors utilized a doublechamber PA cell; the absorption determination was obtained through the measurement of the thermal effusivity of the binary system substance-skin. The model employed by Gutierrez-Juarez and co-workers (that assumes that the effective thermal effusivity of the binary system corresponds to that of a two-phase system) was experimentally applied to study different topically applied substances, in different parts of the body. The corresponding relative concentrations of substances as a function of time were determined by fitting a sigmoidal function (for ketoconazol and sunscreen) or an exponential function (for nitrofurazona, vaseline and vaporub) to the experimental data.

Pedrochi and co-workers (2005) employed PAS measurements to evaluate the penetration rate of different sunscreens into human skin in vivo. Their results showed that the diminution rate of the sunscreen amount in the skin surface depends on the form of the product: sunscreens in cream form tend to present faster reduction after application in skin. This leads to the conclusion that sunscreens in gel form are more adequate (presenting longer protection against UV radiation).

Another transdermal drug delivery study is the work of Truite et al. (2007), which employed PAS measurements in the ex vivo determination of the penetration rate of different phytotherapic formulations (with and without salicylic acid) for treatment of vitiligo. Measurements were performed as a function of time in rabbits. PA depth monitoring 
showed that both formulations propagated through the skin up to the melanocytes region, leading the authors to suggest that the delivery of the active agents may occur even without the use of queratinolitic substances (that are not really recommended, since they are known to induce side effects in animals).

The PA technique can be employed to study the penetration kinetics of topically applied products not only as a function of product composition, but also according to the application method. Phonophoresis is the utilization of ultrasound (US) waves to enhance the delivery of topically applied substances (Byl, 1995). In physiotherapy practice, phonophoresis is one of the various strategies developed to overcome the skin's resistance in transdermal drug delivery, enhancing skin permeability (Duangit et al., 2011).

In the last years, comparative studies between massage and phonophoresis (in its different modes) as application methods for different anti-inflammatories have been in the front line of research at the FASBio/UNIVAP; in the experiments, transdermal drug delivery has been evaluated through PA measurements as a function of time after topical application of different drugs in the forearm region, using manual massage or phonophoresis.

Results indicate that different products present distinct absorption times (depending on the vehicle employed, for example); the application method also affects the typical time constant of drug penetration into skin, though not for all tested formulations.

In the following subsections, we present one experiment performed at FASBio/UNIVAP in which the penetration kinetics of the pharmaco Cordia verbenacea DC (Acheflan) in the human skin was evaluated through PA measurements as a function of time for each of the application methods: massage and phonophoresis.

\subsubsection{Materials and methods}

The pharmaco Cordia verbenacea DC (Acheflan) is a topic usage anti-inflammatory medication widely employed in medicine, having alpha-humulen and trans-caryophyllen as active agents. Our experiment aimed to evaluate the penetration kinetics of Acheflan in the human skin (massage versus phonophoresis) through in vivo PA measurements.

The survey was conducted in 10 volunteers (four men and six women) aged between 18 and 30 years. The following inclusion criteria were adopted: (i) absence of ulcers or any change in dermatology distal forearm and wrist; (ii) not being allergic to any component of the formula topically applied; (iii) absence of metal implants in the wrist or forearm; (iv) absence of stomach pain complaints; and (v) not being pregnant.

The protocol for cleaning prior to drug application consisted of cleaning the skin area to be evaluated (region near the distal forearm and right ulnar artery) with cotton soaked in $70 \%$ alcohol. The area of topical application was then demarcated and Cordia verbenacea DC (essential oil $5.0 \mathrm{mg} / \mathrm{g}$ ) was applied by rubbing the head of the ultrasound therapy equipment configured for continuous mode and intensity of $1.2 \mathrm{~W} / \mathrm{cm}^{2}$, but switched off, for five minutes. This procedure was repeated on the opposite forearm with the ultrasound therapy equipment turned on, also for five minutes.

PA measurements employed the same experimental system described in section 3.2.1. During measurements, the volunteers were positioned adjacent to the assembly with an aluminum foil $(60 \mu \mathrm{m}$ thick) sealing the PA cell and the distal forearm positioned in direct contact with it, as proposed by Bernengo et al. (1998). For an aluminum foil with this thickness, the cutoff frequency is approximately $7 \mathrm{kHz}$; in the present study, the modulation 
frequency employed was $17 \mathrm{~Hz}$, so that the foil can be considered as thermally thin (Rosencwaig, 1980).

Each measurement series consisted of 40 readings (one each two seconds, for a total time of 80 seconds), repeated 10 times for each application form, with rest intervals of 100 seconds between successive series (total time of 30 minutes for each volunteer and application method). The software "SISCOMF" (developed at UNIVAP) was employed for data acquisition.

In order to analyze the typical time constant for the penetration of the applied drug, the experimental curves were fitted by the Boltzmann equation:

$$
\operatorname{PA}(\mathrm{t})=\frac{\mathrm{A}_{1}-\mathrm{A}_{2}}{1+\mathrm{e}^{\left(\mathrm{t}-\mathrm{t}_{0}\right) / \mathrm{dt}}}+\mathrm{A}_{2}
$$

The Boltzmann curve is a S-shaped curve in which $A_{1}$ is the initial signal amplitude, $A_{2}$ the final signal amplitude, $\mathrm{t}_{0}$ is the half-absorption time and $\mathrm{dt}$, the time interval such as $67 \%$ of the penetration process occurs between $t_{0}-d t$ e $t_{0}+d t$.

Analysis of the PA data was performed with the aid of the software Microcal Origin ${ }^{\circledR} 7.5$ (employed for the generation of the fitting curves); statistical analysis was performed with GraphPad Instat ${ }^{\circledR}$ 3.0.

\subsubsection{Results and discussion}

Figure 3 shows an example of PA data measurements as a function of time fitted by a Boltzmann curve.

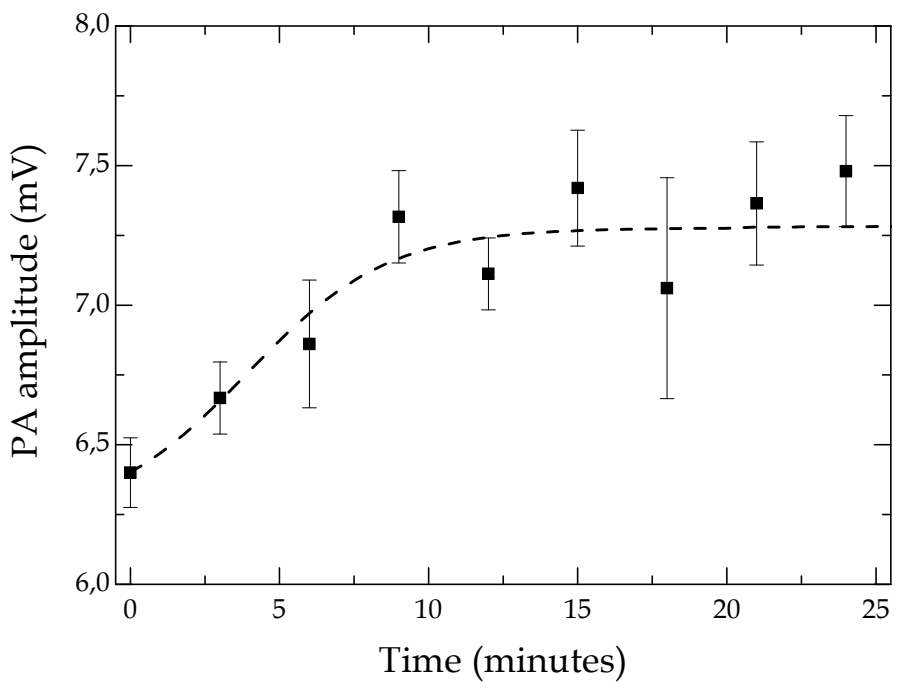

Fig. 3. Example of a Boltzmann curve (dashed line) fitting PA data obtained for one of the volunteers after phonophoresis application of the pharmaco Cordia verbenacea DC (Acheflan) 
The experimental results obtained (average values for each parameter of the fitting curve) are summarized in Table 3; interpretation of such results must consider that the initial amplitude $\left(\mathrm{A}_{1}\right)$ of the PA signal corresponds to the system formed by the applied drug+skin, while the final amplitude $\left(\mathrm{A}_{2}\right)$ corresponds to the skin only, with the product having penetrated beyond the layer responsible for the generation of the PA signal (about $30 \mu \mathrm{m}$, in the present case).

\begin{tabular}{|l|c|c|c|c|c|}
\hline Application Method & $\mathrm{A}_{1}$ (u.a) & $\mathrm{A}_{2}$ (u.a) & $\mathrm{t}_{0}$ & $\mathrm{Dt}$ & $\mathrm{t}_{\mathrm{s}}\left(\mathrm{t}_{0}+\mathrm{dt}\right)$ \\
\hline Massage & $0,66 \pm 0,04$ & $0,70 \pm 0,02$ & $7 \pm 2$ & $4 \pm 2$ & $11 \pm 2$ \\
\hline Phonophoresis & $0,65 \pm 0,03$ & $0,72 \pm 0,04$ & $5 \pm 1$ & $1,3 \pm 0,3$ & $7 \pm 1$ \\
\hline
\end{tabular}

Table 3. Average values ( \pm standard error) for $A_{1}$ and $A_{2}$ (in arbitrary units), $t_{0}$ and $d t$ (in minutes), for each of the application methods $(\mathrm{N}=10)$

In order to understand if penetration was effective, first of all, it is imperative to evaluate if the difference between $A_{1}$ and $A_{2}$ is statistically significant. Therefore, initially a paired t-test was carried on to verify if there was significant difference between $A_{1}$ and $A_{2}$ for each application method employed (indicating significant penetration of the applied product). This was verified for both application methods; however, this difference is more evident for phonophoresis application, in which the difference between the initial and the final signal presents $\mathrm{p}=0,011$ ( $\mathrm{p}=0,066$ was found for massage application).

Statistical tests were also employed in the comparison between the two application methods (massage and phonophoresis); no statistical significance was found for $t_{0}$ and $d t$. Considering $t_{S}=\left(t_{0}+d t\right)$ as the total effective penetration time for the epidermal layer under study, the results obtained (average \pm error, $N=10$ ) are $11( \pm 2)$ minutes (for massage application) and $7( \pm 1)$ minutes (for phonophoresis application). The paired t-test for this parameter shows $\mathrm{p}=0,073$.

Experiments performed at FASBio/UNIVAP show that the form of application can influence the kinetics of transdermal drug delivery, depending on the applied product. In the experiment presented here, significant penetration has been reported for both forms of administration (massage and phonophoresis); PA measurements showed that effective penetration is at least more evident after phonophoresis application, when compared to massage application.

\section{Conclusion and perspectives}

The possibility of performing in vivo studies brings great value to the use of the PA technique in experimental skin research. The potential and relevance of PA measurements in this field have been shown by a large range of experiments being performed by different research groups around the world - actually, the examples here presented must be seen as a sample of what has been done.

PA measurements in vivo are able to detect alterations in skin pigmentation. Even in skin regions normally protected from sun exposure, the PA signal level tends to follow clinical classification; actually, the use of the PA technique goes one step ahead, allowing comparative and quantitative research through simple, direct measurements.

Topical drug application has been employed in the treatment of many pathological processes; its efficiency is associated to the efficiency of transdermal drug delivery. PA 
measurements have been sucessfully employed in transdermal drug delivery studies, allowing a quantitative analysis of the kinetics and effectivity of drug delivery. Different PA experiments point to the fact that gel formulations tend to be more adequate for topical use. Depending on the topically applied product, the form of application can also be determinant in the kinetics of transdermal drug delivery.

Measurements already performed indicate various perspectives for future research, such as: i) the determination of the skin oiliness level; ii) analysis of skin lesions; iii) studies on the photostability of sunscreens and even determination of the sun protection factor (SPF) of sunscreens (through PAS measurements); and iv) further studies on formulation and application form of a wide range of topically applied products.

\section{Acknowledgment}

The authors acknowledge Fapesp and $\mathrm{CNPq}$ for financial support of biomedical research being developed at FASBio/UNIVAP, São José dos Campos (SP), involving the characterization of human skin and transdermal drug delivery of topically applied products.

\section{References}

Acosta-Avalos, D.; Alvarado-Gil, J.J.; Vargas, H.; Frías-Hernández, J.; Olalde-Portugal, V.; Miranda, L.C.M. (1996) Photoacoustic monitoring of the influence of arbuscular mycorrhizal infection on the photosynthesis of corn (Zea mays L.). Plant Science, v.119, n.1-2, pp.183-190; doi:10.1016/0168-9452(96)04454-8

Aqil, M.; Abdul, A.; Yasmin, S.; Asgar, A. (2007) Status of terpenes as skin penetration enhancers. Drug Discovery Today (Oxford), v.12, n.23/24, pp.1061-1067.

Balderas-Lopez, J.A.; Moreno-Márquez, M.M.; Martínez, J.L.; Sánchez-Sinencio, F. (1999) Thermal characterization of some dental resins using the photoacoustic phase lag discontinuites. Superficies y Vacio, v.8, pp.42-45.

Balderas-Lopez, J.A.; Mandelis, A. (2001) Thermal diffusivity measurements in the photoacoustic open-cell configuration using simple signal normalization techniques. Joumal of Applied Physics, v.90, n.5. pp.2273-2279.

Balogun, O.; Regez, B.; Zhang, H.F.; Krishnaswamy, S. (2009) Real time, full-field imaging of photoacoustic generated signals for biomedical applications, ICPPP15 - Book of Abstracts, 15th International Conference on Photoacoustic and Photothermal Phenomena, pp.77, Leuven, Belgium, July 19-23, 2009.

Baumann, L. (2006a) New Skin Typing System. Skin \& Aging , v.14, n.2, pp.60-64.

Baumann, L. (2006b) The Skin Type Solution. Bantam Books, ISBN-10: 0-553-80422-7, New York, NY.

Beard, P. (2009) High resolution spectroscopic photoacoustic imaging for characteristic tissue structure and function, ICPPP15 - Book of Abstracts, 15th International Conference on Photoacoustic and Photothermal Phenomena, pp.79, Leuven, Belgium, July 19-23, 2009.

Benamar, N.; Laplante, A.F.; Lahjomri, F.; Leblanc, R.M. (2004) Modulated photoacoustic spectroscopy study of an artificial tanning on human skin induced by dihydroxyacetone. Physiological Measurement, v.25, n.5, pp.1199-1210.

Benech-Kieffer, F.; Wegrich, P.; Schwarzenbach, R.; Klecak, G.; Weber, T.; Leclaire, J.; Schaefer, H. (2000) Percutaneous Absorption of Sunscreens in vitro: Interspecies 
Comparison, Skin Models and Reproducibility Aspects. Skin Pharmacology and Physiology, v.13, pp.324-335; doi: 10.1159/000029940

Bernengo, J.C.; Gasquez, C; Falson-Rieg, F. (1998) Photoacoustics as a tool for cutaneous permeation studies. High Temperature-High Pressure, v.30, n.5, pp.619-624.

Bodzenta, J.; Bukowski, R.J.; Christ, A.; Pogoda, T. (2002) Photoacoustic detection of drug diffusion into a membrane: theory and numerical analysis. International Journal of Heat and Mass Transfer, v.45, n.22, pp.4515-4523; doi:10.1016/S0017-9310(02)00155-2

Byl, N.N. (1995) The Use of Ultrasound as an Enhancer for Transcutaneous Drug Delivery: Phonophoresis. Physical Therapy, v.75, n.6, pp.539-553.

Cahen, D.; Bults, G.; Garty, H.; Malkin, S. (1980) Photoacoustic in life sciences. J. Biochemical Biophysical Methods, v.3 (5), 1980, pp.293-310.

Duangjit, S.; Opanasopit, P.; Rojanarata, T.; Ngawhirunpat, T. (2011) Characterization and In Vitro Skin Permeation of Meloxicam-Loaded Liposomes versus Transfersomes. Journal of Drug Delivery, v.2011, ID 418316; doi:10.1155/2011/418316

Fitzpatrick, T.B. (1988) The validity and practicality of sun-reactive skin types I through VI. Archives of Dermatology, v.124, pp.869-871.

Gao, C.M.; Zhang, S.Y.; Zhang, Z.; Shui, X.J. (2005) Thermal diffusivity of porcine tissues characterized by photoacoustic piezoeletric technique. Journal of Physics IV (France), v.125, pp.777-779; doi:10.1051/jp4:2005125179

Gutierrez-Juarez, G.; Vargas-Luna, M.; Cordova, T.; Varela, J.B.; Bernal-Alvarado, J.J.; Sosa, M. (2002) In vivo measurement of human skin absorption of topically applied substances by a photoacoustic technique. Physiological Measurement, v.23, pp.521532.

Hahn, B.D.; Neubert, R.H.H.; Wartewig, S.; Lasch, J. (2001) Penetration of compounds through human stratum corneum as studied by Fourier transform infrared photoacoustic spectroscopy. Journal of Controlled Release, v.70, n.3, pp.393-398.

Herbert, S.K.; Han, T.; Vogelmann, T.C. (2000) New applications of photoacoustics to the study of photosynthesis. Photosynthesis Research, v.66, n.1-2, pp.13-31; doi: 10.1023/ A:1010788504886

$\mathrm{Hu}$, S.; Wang, L.V. (2010) Photoacoustic imaging and characterization of the microvasculature, Journal of Biomedical Optics, v.15, pp.011-101; doi:10.1117/1.3281673

Li, T.; Dewhurst, R.J. (2010) Photoacoustic imaging in both soft and hard biological tissue. Journal of Physics: Conference Series, v.214, 012028; doi: 10.1088/17426596/214/1/012028

Lopez, T.; Picquart, M.; Aguilar, D.H.; Quintana, P.; Alvarado-Gil, J.J.; Pacheco, J. (2005) Photoacoustic monitoring of dehydration in sol-gel titania emulsions. Journal of Physics IV (France), v.125, pp.583-585; doi:10.1051/jp4:2005125134

McDonald, F.A.; Wetsel G.C. (1978) Generalized theory of the photoacoustic effect, Journal of Applied Physics, v.49, pp.2313.

Malkin, S.; Puchenkov, O.V. (1997) The photoacoustic effect in photosynthesis. In Progress in Photothermal and Photoacoustic Science and Technology: Life and Earth Sciences (Mandelis, A., and Hess, P., editors), SPIE, ISBN 0-8194-2450-1, Washington, USA.

Marquezini, M.V.; Cella, N.; Mansanares, A.M.; Vargas, H.; Miranda, L.C.M. (1990) Open photoacoustic cell spectroscopy. Measurement Science \& Technology, v.2, pp.396-401. 
Melo, J.O.; Pedrochi, F.; Baesso, M.; Hernandes, L.; Truiti, M.; Baroni, S.; Bersani-Amado, C. (2011) Evidence of Deep Percutaneous Penetration Associated with AntiInflammatory Activity of Topically Applied Helicteres gardneriana Extract: A Photoacoustic Spectroscopy Study. Pharmaceutical Research, v.28, n.2, pp.331-336; doi: 10.1007/s11095-010-0279-3

Nicoli, S.; Padula, C.; Aversa, V.; Vietti, B.; Wertz, P.W.; Millet, A.; Falson, F.; Govoni, P.; Santi, P. (2008) Characterization of Rabbit Ear Skin as a Skin Model for in vitro Transdermal Permeation Experiments: Histology, Lipid Composition and Permeability. Skin Pharmacology and Physiology, v.21, pp.218-226; doi: $10.1159 / 000135638$

Pedrochi, F.; Sehn, E.; Medina, A.N.; Bento, A.C.; Baesso, M.L.; Storck, A.; Gesztesi, J.L. (2005) Photoacoustic Spectroscopy to Evaluate the Penetration Rate of Three Different Sunscreens into Human Skin in vivo. Journal of Physics IV (France), v.125, pp.757-759; doi:10.1051/jp4:2005125174

Qiu, P.F.; Zhang, S.Y.; Shui, X.J. (2008) Photoacoustic study of thermal properties of biological tissues detected by PVDF film transducer. European Physics Journal Special Topics, v.153, pp.487-490.

Rezende, D.V.; Nunes, O.A.C.; Oliveira, A.C. (2009) Photoacoustic Study of Fungal Disease of Açai (Euterpe oleracea) Seeds. International Journal of Thermophysics, v.30, n.5, pp.1616-1625; doi: 10.1007/s10765-009-0655-6

Rosencwaig, A.; Gersho, A. (1976) Theory of the photoacoustic effect with solids. Journal of Applied Physics, v.47, pp.64-69.

Rosencwaig, A. (1980) Photoacoustics and Photoacoustic Spectroscopy. John Wiley \& Sons, ISBN 0-471-04495-4, New York, USA.

Savateeva, E.V.; Karabutov, A.A.; Oraevsky, A.A. (2001) Proceedings of SPIE 4256, pp.61-69.

Schmidt, W.D.; Fassler, D.; Zimmermann, G.; Liebold, K.; Wollina, U. (2000) Non-contacting diffuse VIS-NIR spectroscopy of human skin for evaluation of skin type and timedependent microcirculation. Progress in biomedical optics and imaging, v.1, n.31, pp.91-102.

Silva, W.J.; Prioli, L.M.; Magalhães, A.C.N.; Pereira, A.C.; Vargas, H.; Mansanares, A.M.; Cella, N.; Miranda, L.C.M.; Alvarado-Gil, J.J. (1995) Photosynthetic $\mathrm{O}_{2}$ evolution in maize inbreds and their hybrids can be differentiated by open photoacoustic cell technique. Plant Science, v.104, n.2, pp.177-181; doi:10.1016/0168-9452(94)04026-D

Simon, G.A.; Maibach, H.I. (2000) The Pig as an Experimental Animal Model of Percutaneous Permeation in Man: Qualitative and Quantitative Observations - An Overview. Skin Pharmacology and Applied Skin Physiology, v.13, pp.229-234; doi: 10.1159/000029928

Sui, X.; Sun, J.; Wang, S.; Li, W.; Hu, L.; Meng, F.; Fan, Y.; Zhang, A. (2011) Photosynthetic induction in leaves of two cucumber genotypes differing in sensitivity to low-light stress. African Journal of Biotechnology, v.10, n.12, pp. 2238-2247.

Swearingen JA, Holan SH, Feldman MM, Viator JA. (2010) Photoacoustic discrimination of vascular and pigmented lesions using classical and Bayesian methods. Journal of Biomedical Optics, v.15, n.1, 016019; doi: 10.1117/1.3316297

Truite, C.V.R.; Philippsen, G.S.; Ueda-Nakamura, T.; Natali, M.R.M.; Dias Filho; B.P.; Bento, A.C.; Baesso, M.L.; Nakamura, C.V. (2007) Photochemistry and Photobiology, v.83, pp.1529-1536; doi: 10.1111/j.1751-1097.2007.00197.x 
Vargas, H.; Miranda, L.C.M. (1988) Photoacoustic and related photothermal techniques. Physics Reports, v.161, n.2, pp.43-101.

Viator, J.A.; Komadin, J.; Svaasand, L.O.; Aguilar, G.; Choi, B.; Nelson, J.S. (2004) A Comparative Study of Photoacoustic and Reflectance Methods for Determination of Epidermal Melanin Content. Journal of Investigative Dermatology, v.122, pp.14321439. 


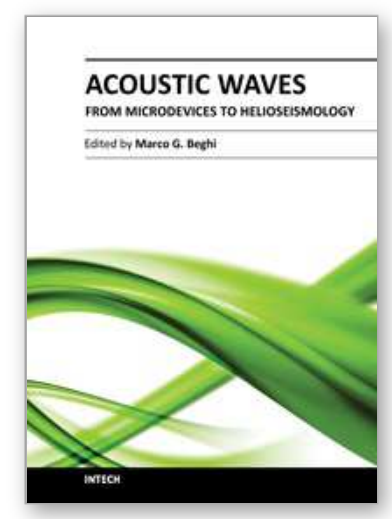

\author{
Acoustic Waves - From Microdevices to Helioseismology \\ Edited by Prof. Marco G. Beghi
}

ISBN 978-953-307-572-3

Hard cover, 652 pages

Publisher InTech

Published online 14, November, 2011

Published in print edition November, 2011

The concept of acoustic wave is a pervasive one, which emerges in any type of medium, from solids to plasmas, at length and time scales ranging from sub-micrometric layers in microdevices to seismic waves in the Sun's interior. This book presents several aspects of the active research ongoing in this field. Theoretical efforts are leading to a deeper understanding of phenomena, also in complicated environments like the solar surface boundary. Acoustic waves are a flexible probe to investigate the properties of very different systems, from thin inorganic layers to ripening cheese to biological systems. Acoustic waves are also a tool to manipulate matter, from the delicate evaporation of biomolecules to be analysed, to the phase transitions induced by intense shock waves. And a whole class of widespread microdevices, including filters and sensors, is based on the behaviour of acoustic waves propagating in thin layers. The search for better performances is driving to new materials for these devices, and to more refined tools for their analysis.

\title{
How to reference
}

In order to correctly reference this scholarly work, feel free to copy and paste the following:

Jociely P. Mota, Jorge L.C. Carvalho, Sérgio S. Carvalho and Paulo R. Barja (2011). Photoacoustic Technique Applied to Skin Research: Characterization of Tissue, Topically Applied Products and Transdermal Drug Delivery, Acoustic Waves - From Microdevices to Helioseismology, Prof. Marco G. Beghi (Ed.), ISBN: 978-953307-572-3, InTech, Available from: http://www.intechopen.com/books/acoustic-waves-from-microdevices-tohelioseismology/photoacoustic-technique-applied-to-skin-research-characterization-of-tissue-topically-appliedproduc

\section{INTECH}

open science | open minds

\section{InTech Europe}

University Campus STeP Ri

Slavka Krautzeka 83/A

51000 Rijeka, Croatia

Phone: +385 (51) 770447

Fax: +385 (51) 686166

www.intechopen.com

\section{InTech China}

Unit 405, Office Block, Hotel Equatorial Shanghai

No.65, Yan An Road (West), Shanghai, 200040, China 中国上海市延安西路65号上海国际贵都大饭店办公楼405单元

Phone: +86-21-62489820

Fax: +86-21-62489821 
(C) 2011 The Author(s). Licensee IntechOpen. This is an open access article distributed under the terms of the Creative Commons Attribution 3.0 License, which permits unrestricted use, distribution, and reproduction in any medium, provided the original work is properly cited. 